\title{
O Ensino de Química no Ensino CTS Brasileiro: Uma Revisão Bibliográfica de Publicações em Periódicos
}

\author{
Chemistry Teaching in Brazilian CTS Teaching: a Bibliographic
} Review of Journal Articles

\author{
Júlia D. Bouzon, Juliana B. Brandão, Taís C. dos Santos e Álvaro Chrispino
}

Resumo: Este trabalho apresenta uma revisão bibliográfica de publicações em periódicos a partir do mapeamento de palavraschave, autores e obras mais citadas sobre o ensino de química com enfoque CTS no Brasil. Para o desenvolvimento desta pesquisa, foram consultados 244 artigos encontrados em 31 revistas brasileiras de ensino e educação, indexadas com Qualis A1, A2 e B1 pela Coordenação de Aperfeiçoamento de Pessoal de Nível Superior (CAPES), publicados de 1996 a 2016. A fim de estabelecer um recorte metodológico, pesquisou-se neste conjunto trabalhos relacionados ao ensino de química, resultando em 41 artigos que constituíram o objeto desta pesquisa. A partir da análise das informações, verificou-se que o acrônimo CTS foi a palavra-chave de maior relevância dentro da área. Além disso, foi feito um estudo sobre a comunicação entre os autores desses artigos, com destaque para as pesquisadoras Carmem Lúcia Costa Amaral, Vânia Gomes Zuin e Maria DeLourdes Maciel, que são as que estabelecem maior relação com os demais autores dos textos analisados. O estudo realizado revelou ainda que Wildson Santos, além de ser o autor mais citado nesse universo, tem a obra Educação em Química: compromisso com a cidadania, em parceria com Roseli Pacheco Schnetzler, como a mais referenciada na área de ensino de química com enfoque CTS no Brasil.

Palavras-chave: CTS. Ensino de Química. Revisão

Bibliográfica.

\begin{abstract}
This work presents a bibliographic review of publications in journals from the mapping of keywords, authors and most cited works on chemical education with a CTS approach in Brazil. For the development of this research, 244 articles were consulted in 31 Brazilian journals of teaching and education, indexed with Qualis A1, A2 and B1 by the Coordenação de Aperfeiçoamento de Pessoal de Nível Superior (CAPES), published from 1996 to 2016. In order to establish a methodological cut, we have investigated in this set works related to the teaching of chemistry, resulting in 41 articles that constituted the object of this research. From the analysis of the information it was verified that the acronym CTS was the the most relevant keyword in this area. In addition, a study was carried out on the communication between the authors of these articles, especially the researchers Carmem Lúcia Costa Amaral, Vânia Gomes Zuin and Maria DeLourdes Maciel, who are the ones who establish a greater relationship with the other authors of the texts analyzed. The study also revealed that Wildson Santos, besides being the most cited author in this universe, has the work Education in Chemistry: commitment to citizenship, in partnership with Roseli Pacheco Schnetzler, as the most referenced in the area of chemistry education with a CTS approach in Brazil.
\end{abstract}

Keywords: CTS. Chemistry Education. Bibliographic Review.

\footnotetext{
Júlia Damazio Bouzon (juliabouzon@ gmail.com), mestre em Ensino de Ciências da Natureza Universidade Federal Fluminense (UFF), é professora no Colégio Pedro II - Campus Centro. Rio de Janeiro, RJ - BR. Juliana Barreto Brandão (profjulianabrandao@gmail.com), mestre em Ensino de Ciências da Natureza pela UFF, é professora do Centro Federal de Educação Tecnológica Celso Suckow da Fonseca (CEFET/RJ). Rio de Janeiro, RJ - BR. Taís Conceição dos Santos (taisquim@ @otmail.com), doutora em Ensino em Biociências e Saúde pela Fundação Oswaldo Cruz, é professora do CEFET/RJ. Rio de Janeiro, RJ - BR. Álvaro Chrispino (alvaro.chrispino@ gmail.com), doutor em Educação pela Universidade Federal do Rio de Janeiro, é professor do CEFET/RJ. Rio de Janeiro, RJ - BR. Recebido em 23/11/2017, aceito em 01/06/2018
}

A seção "Cadernos de Pesquisa" é um espaço dedicado exclusivamente para artigos inéditos (empíricos, de revisão ou teóricos) que apresentem profundidade teórico-metodológica, gerem conhecimentos novos para a área e contribuições para o avanço da pesquisa em Ensino de Química. 
A química ainda é vista como uma ciência de difícil compreensão pela maioria das pessoas. Um dos motivos que justificam este pensamento é a forma meramente propedêutica pela qual os conteúdos desta disciplina são ensinados aos alunos, de maneira descontextualizada e fragmentada, tornando-se distante de seu cotidiano. Na interpretação de Auler (2003, p. 78)

[...] pode ser interessante ensinar as disciplinas, por elas mesmas, a futuros especialistas, mas não devemos nos assombrar se, quando nosso ensino está majoritariamente centrado sobre os interesses dos cientistas, os jovens acabem ficando desgostosos com o ensino de ciências.

Tendo isso em vista, o ensino focado na tríade CiênciaTecnologia-Sociedade (CTS) vem ao encontro desta problemática, como uma abordagem que busca superar esse quadro e que se preocupa em ampliar o processo de ensino-aprendizagem para além dos muros da escola, se utilizando da compreensão dos conteúdos não com um fim em si mesmo, mas como um meio capaz de promover a formação crítica do indivíduo. De acordo com Manassero e Vázquez (2001, p. 16),

No espírito desse movimento está o desejo de oferecer, através da educação científica, uma visão mais autêntica da ciência e da tecnologia em seu contexto social, distantes de imagens mitificadas e tendenciosas (cientificismo e tecnocracia) ao mesmo tempo em que se reconhece a tecnologia como uma atividade diferente, integrada e equiparável com a ciência, e não só como mera ciência aplicada.

Essas imagens mitificadas e tendenciosas fazem com que os alunos percebam a ciência como neutra, isenta de influência política, social, ideológica, econômica, dentre outras. Na visão de Auler e Delizoicov (2001), esta neutralidade é considerada o mito original da ciência e abrange concepções como se a ciência fosse salvadora, infalível, o suporte para a produção de tecnologias que serão sempre benéficas para a sociedade, ou seja, quanto mais ciência, mais tecnologia e, consequentemente, mais progresso (Bazzo et al., 2003; Auler e Delizoicov, 2001; Manassero e Vázquez, 2001).

Apesar de ser uma alternativa para a superação desses mitos, é importante ressaltar a complexidade da abordagem CTS que, segundo Aikenhead (2005), leva a variadas concepções sobre o assunto, demonstrando a diversidade do tema, um fato positivo para o ensino. Contudo, ao mesmo tempo, mostra a dificuldade de se chegar a um consenso, o que pode ser um empecilho para os professores que desejam se utilizar desta abordagem. Sendo assim, neste trabalho destacamos a concepção de CTS na visão de Cutcliffe (2003, p. 18):

A missão central do campo [acadêmico] CTS, até o momento, tem sido expressar a interpretação da ciência e da tecnologia como um processo social. Deste ponto de vista, a ciência e a tecnologia são vistas como projetos complexos em que os valores culturais, políticos e econômicos nos ajudam a configurar os processos tecnocientíficos, que, por sua vez, afetam os mesmos valores e a sociedade que os detém.

Ao pensar essa interpretação no contexto do ensino de ciências/química, é necessário explicitar que o ensino CTS requer maior atenção do professor no que diz respeito a sua prática, desde a preparação da aula até a condução da mesma, a fim de se obter um clima tanto metodológico quanto afetivo que sejam positivos para o aluno. No entanto, o educador pode encontrar dificuldades para promover essa mudança e, com o objetivo de auxiliá-lo, Acevedo Díaz (1996) propõe estratégias de ensino-aprendizagem e descreve algumas funções características do professor que se utiliza da educação CTS.

Essa discussão nos leva a refletir sobre a produtividade do ensino com enfoque CTS no Brasil. Auler (2007, p. 1) afirma que as iniciativas nesta área ainda são muito modestas e acredita que, para mudar esse panorama, é necessária intensa mudança curricular. Ou seja,

configurações curriculares mais sensíveis ao entorno, mais abertas a temas, a problemas contemporâneos marcados pela componente científico-tecnológica, enfatizando-se a necessidade de superar configurações pautadas unicamente pela lógica interna das disciplinas, passando a serem configuradas a partir de temas/problemas sociais relevantes, cuja complexidade não é abarcável pelo viés unicamente disciplinar.

Além disso, é importante acrescentar que os documentos oficiais, como Parâmetros Curriculares Nacionais, Diretrizes Curriculares Nacionais, Matriz de Referência do Exame Nacional do Ensino Médio, dentre outros, já possuem proposições curriculares que apontam para a abordagem CTS. Todavia, Strieder et al. (2016, p. 100) afirmam que

\section{[...] não é suficiente inserir mudanças nos} documentos curriculares sem promover, de forma articulada, mudanças nas concepções e na prática pedagógica dos professores, até porque crenças e atitudes sobre cidadania, tecnologia, aspectos sociocientíficos, interdisciplinaridade, contextualização e abordagem temática, interferem nas práticas didático-pedagógicas dos docentes.

Concatenando as ideias apresentadas, acreditamos que o uso da abordagem CTS pode ser uma opção para a promoção de um ensino de química voltado para a formação mais crítica 
dos indivíduos, a partir da construção social da ciência e da tecnologia. Com isso, assim como já foi feito para o ensino de biologia através do mesmo banco de dados (Rocha et al., 2017), este trabalho busca fazer uma revisão bibliográfica sobre o ensino de química com enfoque CTS, fazendo uma análise crítica sobre a representação destes no ensino CTS brasileiro, utilizando-se da ferramenta de redes sociais.

$\mathrm{O}$ estudo de redes sociais se originou nas ciências sociais com o antropólogo John Arundel Barnes, o qual considera que "quando estudamos a organização social de uma sociedade simples, visamos compreender sistematicamente todas as maneiras com que os membros da sociedade interagem uns com os outros" (Barnes, 1954, p. 39).

Para a construção de uma rede social, a matemática se utiliza da Teoria dos Grafos. De acordo com esta teoria, "uma rede social, que pode ser modelada por um grafo, é definida como um conjunto de vértices ou atores cujas inter-relações são representadas por arcos" (Chrispino et al., 2013, p. 460).

Para Melo et al. (2016, p. 594),

[...] a análise de rede social nos permite ter uma visão panorâmica de como se comporta uma área, seja ela CTS ou qualquer outra. A metodologia escolhida, ainda que não tão popular quanto outras na área de ensino, apresenta uma visão dos dados capaz de trazer amplitude e o tratamento de um número elevado de dados. Assim como metodologias de análise de conteúdo e suas derivadas, ela apresenta categorizações retiradas do próprio material de análise, porém, não de forma qualitativa, mas quantitativa. Isso permite que trabalhemos tantos artigos quantos a literatura nos dispuser.

Sendo assim, neste trabalho foi utilizada a Teoria dos Grafos para modelar as redes sociais, em especial de palavras-chave e autores de artigos de ensino de química com enfoque CTS no Brasil.

\section{Metodologia}

Para o desenvolvimento dessa pesquisa, consultamos 244 artigos encontrados em 31 revistas brasileiras de ensino e educação, indexadas com Qualis A1, A2 e B1 pela Coordenação de Aperfeiçoamento de Pessoal de Nível Superior (CAPES), publicados de 1996 a 2016. Os artigos foram selecionados a partir da busca em resumos, títulos e/ou palavras-chave que continham o acrônimo CTS e suas derivações, como "Ciência", "Tecnologia" e "Sociedade", "Ciência-Tecnologia-Sociedade", "Ciência e Tecnologia e Sociedade".

As revistas que constam nesse banco de dados são: Acta Scientiae; Alexandria, Revista de Educação em Ciência e Tecnologia; Avaliação; Biodiversidade; Caderno Brasileiro de Ensino de Física; Ciência \& Cognição; Ciência \& Educação;
Ciência e Ensino; Ciência em Tela; Ciências e Ideias; Debates em Educação Científica e Tecnológica; Educação Matemática Pesquisa; Educar em Revista; Ensaio: Pesquisa em Educação em Ciências; Ensino de Ciências e Tecnologia em Revista; Ensino, Saúde e Ambiente; Experiências em Ensino de Ciências; Investigações em Ensino de Ciências; Pesquisa em Educação Ambiental; Química Nova na Escola; Química Nova; Revista Brasileira de Ciência, Tecnologia e Sociedade; Revista Brasileira de Ensino de Ciência e Tecnologia; Revista Brasileira de Ensino de Física; Revista de Ensino de Ciências e Engenharia; Revista de Ensino de Ciências e Matemática - RENCIMA; Revista de Ensino de Engenharia; Revista Brasileira de Pesquisa em Educação em Ciência; Scientia Plena; e Tecnologia e Sociedade.

Dentro dos 244 artigos, uma nova busca foi realizada a fim de identificarmos os artigos que se relacionavam com o ensino de química. Para isto, foram pesquisados em títulos e palavraschave o termo "química" ou outros termos que possuíam relação com o termo química, tendo como resultado 41 artigos (Tabela 1) que foram o nosso objeto de estudo.

Como ferramenta de trabalho, optamos pela análise de rede social que, através de grafos (representação gráfica de uma rede), possibilita perceber a interação entre entes diversos dentro de um universo. $\mathrm{O}$ grafo é constituído de vértices ou atores e arestas, que são as conexões que ligam esses vértices, ou seja, representam os laços de relacionamento entre os mesmos. Neste trabalho, os atores analisados foram as palavras-chave e os autores.

Mesmo que uma rede social, em princípio, nos traga apenas dados quantitativos, ela ainda nos permite fazer uma análise qualitativa a respeito dos dados.

A rede social deste trabalho foi gerada no software NodeXL ${ }^{1}$ que, além de gerar o grafo, permite calcular medidas de centralidade. Estas são graus que indicam as posições dos vértices de uma rede social e possibilitam quantificar a interligação de um ator dentro da rede, podendo ser de diferentes tipos, como por exemplo: de grau de entrada, de proximidade (closeness) e de intermediação (betweenness). Neste caso, usaremos as medidas de centralidade citadas anteriormente.

A medida de centralidade de grau de entrada aponta quantas arestas se ligam a um vértice da rede. Sendo assim, quanto maior for a centralidade de grau, mais relações um vértice (palavra-chave, por exemplo) possui com outros e maior é a sua importância dentro da rede. A medida de centralidade de proximidade (closeness) mede a distância da ligação entre os vértices, o que significa que quanto maior for o grau de proximidade, menor é a distância entre duas palavras-chave e, consequentemente, maior é a comunicação entre elas. Em contrapartida, a medida de centralidade de intermediação (betweenness) indica a capacidade que um vértice tem de relacionar duas sub-redes, isto é, de que forma uma palavrachave consegue intermediar dois ou mais artigos no menor caminho entre eles. Sendo assim, indica o quanto a palavra 
Tabela 1: Lista de artigos analisados organizados por revista

\begin{tabular}{|c|c|}
\hline Revista & Localização \\
\hline Química Nova na Escola & $\begin{array}{l}\text { - FERNANDES, C. S. e MARQUES, C. A. v. 37, n. 4, p. 294-304, } 2013 . \\
\text { - REBELLO, G. A. F. et al. v. 34, n. 1, p. 3-9, } 2012 . \\
\text { - REBELO, I. S. et al. v. } 27, \text { n. 2, p. 30-33, } 2008 . \\
\text { - SILVA, P. S. e MORTIMER, E. F. v. 34, n. 4, p. 240-247, } 2012 . \\
\text { - SILVA, R. O. v. 32, n. 2, p. 90-94, } 2010 . \\
\text { - SOUZA, F. L. e MARTINS, P. v. 33, n. 1, p. 19-24, } 2011 . \\
\text { - ZUIN, V. G. et al. v. } 31 \text {, n. 1, p. 3-8, } 2009 .\end{array}$ \\
\hline Ciência \& Educação & $\begin{array}{l}\text { - FIRME, R. D. N. e AMARAL, E. M. R. v. 17, n. 2, p. 383-399, } 2011 . \\
\text { - FIRME, R. N. e AMARAL, E. M. R. v. 14, n. 2, p. 251-269, } 2008 . \\
\text { - SILVA, E. L. e MARCONDES, M. E. R. v. 21, n. 1, p. 65-83, } 2015 . \\
\text { - ZANOTTO, R. L. et al. v. 22, n. 3, p. 727-740, } 2016 .\end{array}$ \\
\hline Experiências em Ensino de Ciências & $\begin{array}{l}\text { - MATHIAS, G. e AMARAL, C. v. 5, n. 2, p. 107-120, } 2010 . \\
\text { - REGIS, A. C. D. e BELLO, M. E. D. R. B. v. 6, n. 1, p. 95-111, } 2011 . \\
\text { - SANTOS, M. S. et al. v. 5, n. 3, p. 115-121, } 2010 . \\
\text { - XAVIER, P. M. A. et al. v. 8, n. 2, p. 37-50, } 2013 .\end{array}$ \\
\hline Investigações em Ensino de Ciências & $\begin{array}{l}\text { - } \text { AMARAL, C. L. C. et al. v. 14, n. 1, p. 101-114, } 2016 . \\
\text { - MARCONDES, M. E. R. et al. v. 14, n. 2, p. 281-298, } 2009 . \\
\text { - SANTOS, W. L. P. e MORTIMER, E. F. v. 14, n. 2, p. 191-218, } 2016 .\end{array}$ \\
\hline Revista Brasileira de Ensino de Ciências e Tecnologia & $\begin{array}{l}\text { - AZEVEDO, L. A. et al. v. 6, n. 2, p. 41-61, } 2013 . \\
\text { - OLIVEIRA, S. et al. v. 8, n. 4, p. 75-105, } 2015 . \\
\text { - SANTOS, M. S. et al. v. 3, n. 2, p. 98-116, } 2010 .\end{array}$ \\
\hline Ensaio Pesquisa em Educação em Ciências & $\begin{array}{l}\text { - BARBOSA, L. G. D. et al. v. 14, n. 1, p. 113-130, } 2012 . \\
\text { - SANTOS, M. S. et al. v. 14, n. 1, p. 227-239, } 2012 . \\
\text { - SILVA, E. S. e MARCONDES, M. E. R. v. 12, n. 1, p. 101-118, } 2010 .\end{array}$ \\
\hline Ciência \& Ensino & $\begin{array}{l}\text { - FLÔR, C. C. v. 1, p. 1-8, } 2007 . \\
\text { - PIERSON, A. P. H. C. et al. v. 1, p. 1-10, } 2007 . \\
\text { - SANTOS, W. L. P. v. 1, p. 1-12, } 2007 .\end{array}$ \\
\hline Revista de Ensino de Ciências e Matemática & $\begin{array}{l}\text { - SANTOS, M. S. et al. v. 3, n. 3, p. 405-418, } 2012 . \\
\text { - TOMMASIELLO, M. G. C. v. 3, n. 3, p. 231-242, } 2012 . \\
\text { - VASCONCELOS, T. N. H. et al. v. 3, n. 3, p. 377-388, } 2012 .\end{array}$ \\
\hline Alexandria: Revista de Educação em Ciência e Tecnologia & $\begin{array}{l}\text { - OLIVEIRA, A. M. e RECENA, M. C. P. v. 7, n. 1, p. 103-126, } 2014 . \\
\text { - RICHETTI, G. P. e ALVES FILHO, J. P. v. 2, n. 1, p. 85-108, } 2009 .\end{array}$ \\
\hline Ciências \& Cognição & $\begin{array}{l}\text { - KRUGER, J. G. e LEITE, S. Q. M. v. 15, n. 1, p. 171-186, } 2010 . \\
\text { - ZUIN, V. G. et al. v. 13, n. 1, p. 56-64, } 2008 .\end{array}$ \\
\hline Acta Scientiae: revista de ensino de ciências e matemática & - FERREIRA, M. e DEL PINO, J. C. v. 11, n. 1, p. 101-118, 2009. \\
\hline Ensino de Ciências e Tecnologia em Revista & - NIEZER, T. M. e SILVEIRA, R. M. C. v. 4, p. 69-84, 2014. \\
\hline Ensino, Saúde e Ambiente & - PIRES, R. O. et al. v. 9, n. 3, p. 283-296, 2016. \\
\hline Química Nova & - VIANNA, J. F. et al. v. 22, n. 5, p. 765-768, 1999. \\
\hline Revista Brasileira de Pesquisa em Educação em Ciências & - OLIVEIRA, R. D. V. L. e QUEIROZ, G. R. P. C. v. 16, p. 339-360, 2016. \\
\hline Revista Eletrônica Debates em Educação Científica e Tecnológica & - NUNES, A. O. et al. v. 3, n. 2, p. 33-51, 2013. \\
\hline Revista Tecnologia e Sociedade & - FERREIRA, K. M. e VASCONCELOS, T. H. v. 12, n. 24, p. 1-26, 2016. \\
\hline
\end{tabular}

está comprometida com o fluxo de informação, funcionando como "pontes" no conjunto da rede.

Considerando que alguns termos apresentam o mesmo significado, foram criadas algumas equivalências, como, por exemplo, a substituição das palavras-chave "abordagem CTS", "CTSA”, “concepções CTS”, "relações CTS", "relações CTSA" e "atividades CTS" por "CTS", dentre outras do mesmo tipo. 
Depois da rede gerada, foram selecionados, a fim de recorte de pesquisa, os 10 vértices que apresentavam maior grau de entrada e organizou-se uma tabela com os dados de suas diversas medidas de centralidade para posterior análise.

Além disso, com o objetivo de apresentar um resumo sobre as referências mais citadas e um breve panorama sobre a história dos primeiros autores mais relevantes neste campo, duas outras tabelas foram montadas a partir dos 41 artigos relacionados ao ensino de química: a primeira contendo as obras mais citadas por esses artigos e a outra com os primeiros autores mais referenciados pelos mesmos.

\section{Resultados}

A investigação inicial sobre o material selecionado mostra que o número de publicações de artigos sobre ensino de química com abordagem CTS aumentou de 1999 a 2012, apresentando pequena queda em 2011, conforme o Gráfico 1. Essa crescente pode ser justificada pelo fato de que, nesse período, tivemos uma reforma curricular no ensino médio que incorporou "em seus objetivos e fundamentos, elementos dos currículos com ênfase em CTS" (Santos e Mortimer, 2002, p. 114), bem como a realização, em julho de 2010, do II Seminário Ibero-Americano Ciência-Tecnologia-Sociedade no Ensino de Ciências, em Brasília, organizado pela Universidade de Brasília (UnB), Centro Federal de Educação Tecnológica Celso Suckow da Fonseca (CEFET/RJ) e Universidade Cruzeiro do Sul (UNICSUL), que permitiu a reunião dos pesquisadores da área, além de publicações que sintetizaram as grandes ideias apresentadas no evento como, por exemplo, Santos e Auler (2011).

Outra análise realizada foi em relação ao número de artigos sobre o tema publicados em uma mesma revista. De acordo com o Gráfico 2, observa-se que não há grande variação entre os periódicos, destacando-se, no entanto, a revista Química Nova na Escola que, por ser especializada na publicação de artigos sobre química, de modo não surpreendente, apresenta o maior número de publicações investigadas neste trabalho. Ainda em relação a essa análise, cabe ressaltar que as revistas Acta Scientiae:

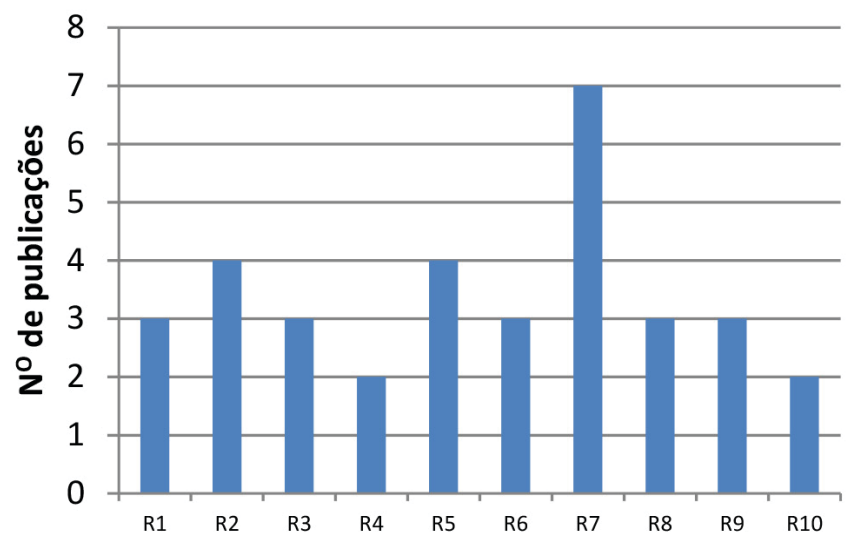

Gráfico 2: Número de publicações CTS/Química por periódico.

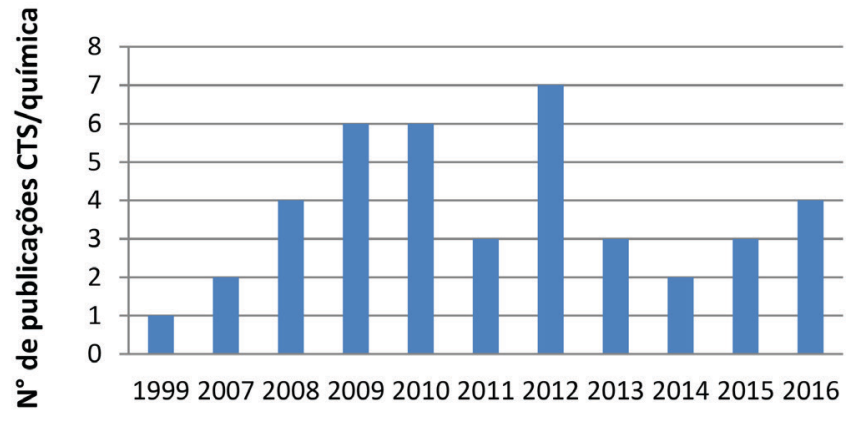

Ano de publicação

Gráfico 1: Número de publicações CTS/Química por ano.

Revista de Ensino de Ciências e Matemática; Ensino de Ciências e Tecnologia em Revista; Ensino, Saúde e Ambiente; Química Nova; Revista Brasileira de Pesquisa em Educação em Ciências; Revista Tecnologia e Sociedade; Revista Eletrônica Debates em Educação Científica e Tecnológica apresentam apenas 1 artigo publicado e não estão representadas no gráfico.

Investigou-se também o vínculo institucional dos autores desses artigos, como mostra o Gráfico 3. Neste Gráfico estão presentes as instituições que possuem mais de um autor contribuindo para este tipo de produção acadêmica. Percebemos, então, que a maior parte das instituições contribui apenas com um autor (e por isso não estão em evidência no Gráfico 3), indicando que a maioria dos artigos foi confeccionada, em parceria, por autores de instituições diferentes, contribuindo para o diálogo entre as mesmas acerca do tema. Por outro lado, merecem destaque a Universidade Cruzeiro do Sul, a USP e a UFSCar, instituições com maior número de autores que publicam sobre o ensino de química com abordagem CTS.

A seguir, passamos ao mapeamento das palavras-chave dos artigos. Essa análise possibilitou identificar os termos mais relevantes no conjunto de publicações estudado, indicando quais temáticas da área de química mais se relacionam com CTS. A partir da organização das mesmas no software citado, gerou-se uma rede social como mostra a Figura 1.

Nessa rede, podemos observar de que maneira as palavraschave se relacionam entre si. Os vértices em negrito

Legenda:

R1 - Revista de Ensino de Ciências e Matemática

R2 - Ciência \& Educação

R3 - Ciência \& Ensino

R4 - Ciências \& Cognição

R5 - Experiências em Ensino de Ciências

R6 - Investigações em Ensino de Ciências

R7 - Química Nova na Escola

R8 - Revista Brasileira de Ensino de Ciências e Tecnologia

R9 - Revista Ensaio: Pesquisa em Educação em Ciências

R10 - Alexandria: Revista de Educação em Ciência e Tecnologia 


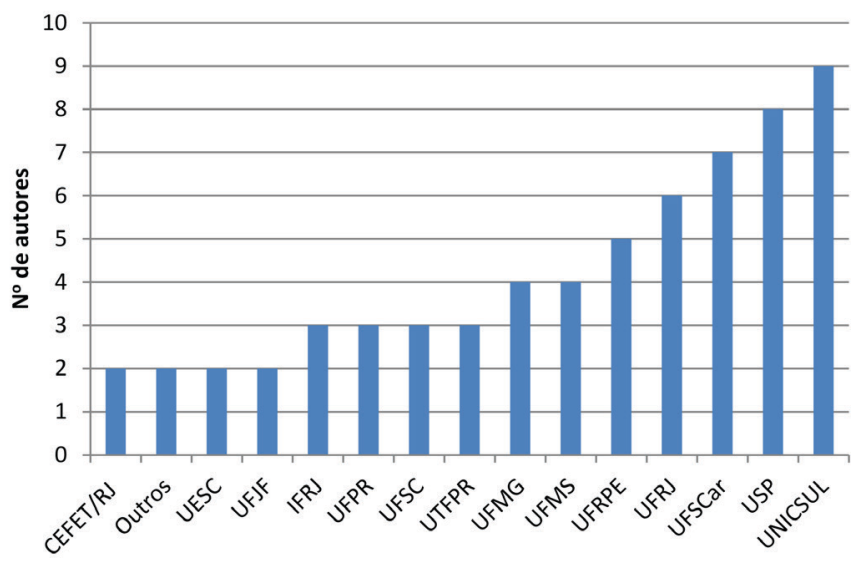

Gráfico 3: Número de autores por instituição.

correspondem às dez que possuem maior grau de entrada, ou seja, aquelas que possuem maior conexão com outros vértices. Além disso, destacamos em vermelho as redes desconexas, que são assim denominadas por não possuírem nenhum vínculo com palavras-chave de outras sub-redes. Isso mostra que, apesar de serem artigos com enfoque CTS, a escolha das palavras-chave dos mesmos não contribui para que a comunidade científica desta área tome conhecimento desses trabalhos facilmente, uma vez que não possuem correlação com a maioria das demais palavras. Ou seja, cada rede desconexa é formada por um grupo de termos que foram indicados como palavras-chave exclusivamente em um dos 41 artigos analisados e, por isso, elas não se relacionam com nenhuma outra sub-rede. Neste sentido, é importante ressaltar que esses artigos só constam na nossa rede devido à análise criteriosa das palavras-chave de todos os artigos do banco de dados que tinham a ver com química e que, caso fosse feita uma busca a partir das expressões "CTS" e/ou "química", os mesmos não estariam neste trabalho.

Os dados da Tabela 2, em consonância com a análise do grafo, nos permitem identificar que "CTS" e "ensino de química" são duas palavras-chave que possuem elevadas medidas de centralidade. Isso indica maior poder de comunicação destas palavras com as demais que constituem a rede, bem como maior capacidade que as mesmas têm de relacionar artigos diferentes, o que era esperado, uma vez que estas palavras caracterizam o objeto principal desta pesquisa.

Do universo de palavras listadas na Tabela 2, é importante destacar que, de modo surpreendente, o acrônimo "EJA" apresenta medidas de centralidade de intermediação e de proximidade superiores a outras palavras-chave que esperávamos que fossem mais relevantes para a pesquisa, como o termo "química". Acreditamos que isso se dá pelo fato de que os professores que atuam neste segmento, provavelmente, buscam aproximar o ensino de química ao cotidiano dos estudantes e, para tal, têm se utilizado da abordagem CTS. Silva e Ploharski (2011, p. 1650) justificam essa aproximação ao cotidiano dos alunos quando defendem que

[...] a metodologia poderá ser um dos agentes causadores do alto índice de evasão escolar nesta modalidade de ensino, uma vez que os professores insistem em utilizar metodologias infantilizadas, sem considerar a rotina de quem estuda e trabalha. No entanto, problemas como esses podem ser resolvidos quando o professor conhece as especificidades desse público e usa do cotidiano do aluno como eixo

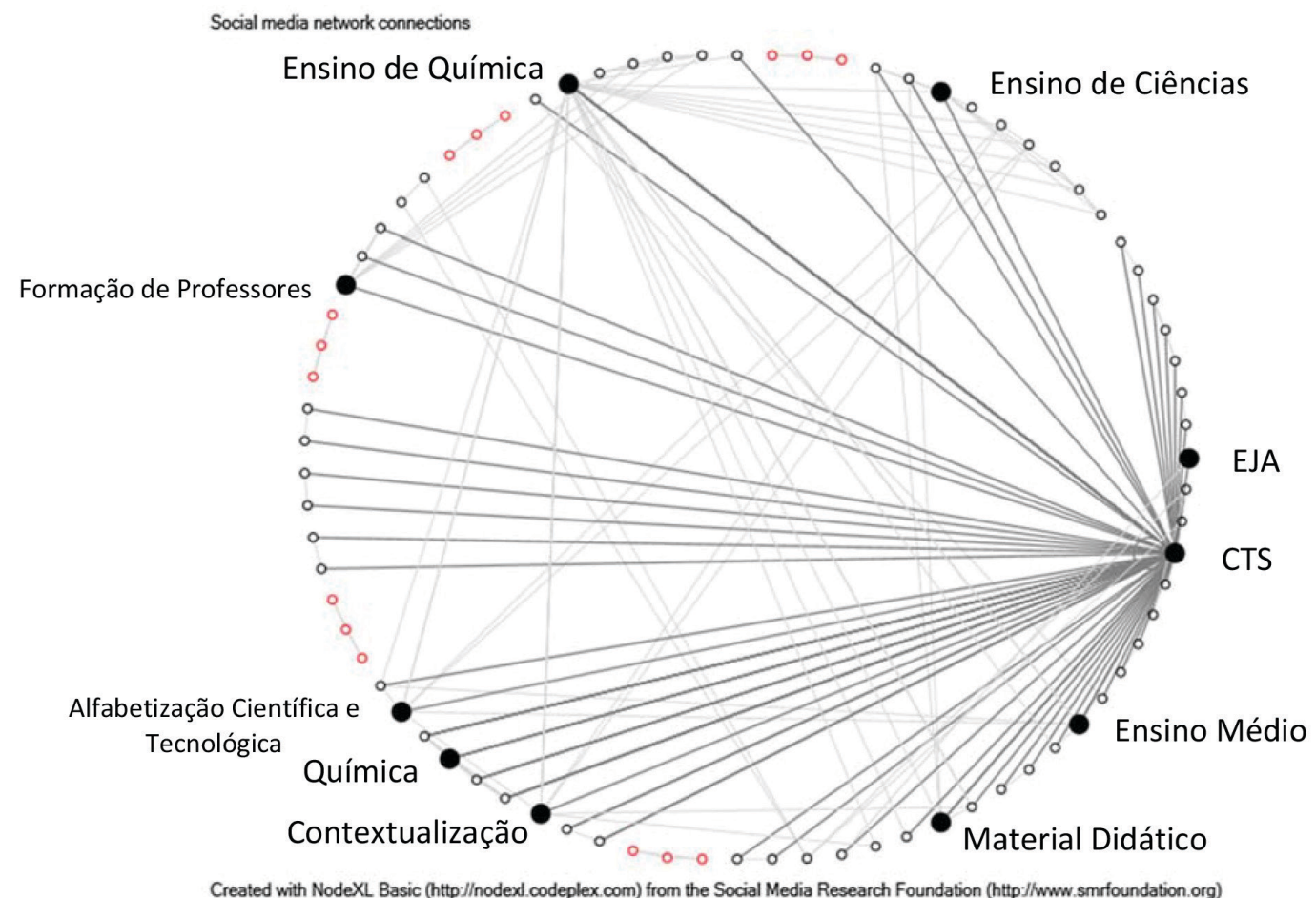

Created with NodeXL Basic (http://nodexl.codeplex.com) from the Social Media Research Foundation (http://www.smrfoundation.org)

Figura 1: Grafo gerado a partir das palavras-chave. 
Tabela 2: Medidas de centralidade para as palavras-chave

\begin{tabular}{lccc}
\hline Palavra-chave & Centralidade de grau & Centralidade de proximidade & Centralidade de intermediação \\
\hline CTS & 49 & 0,013 & 1687,233 \\
Ensino de Química & 17 & 0,008 & 161,067 \\
Formação de Professores & 7 & 0,008 & 232,000 \\
Ensino de Ciência & 8 & 0,008 & 95,967 \\
Material Didático & 5 & 0,008 & 2,967 \\
Contextualização & 7 & 0,008 & 54,467 \\
Alfabetização Científica e & 7 & 0,008 & 31,967 \\
Tecnológica & & & 32,333 \\
EJA & 6 & 0,008 & 0,667 \\
Ensino Médio & 5 & 0,008 & 0,000 \\
Química & 4 & 0,007 & \\
\hline
\end{tabular}

condutor das aprendizagens, essa atitude torna-se imprescindível, para o profissional docente que opta por trabalhar com alunos da EJA, uma vez que se acredita na importância da educação, do ensino sistematizado para a promoção do jovem e do adulto não alfabetizado na atual conjuntura política, econômica e social, promovendo-o como real cidadão.

Além da rede social de palavras-chave, gerou-se outra rede com 86 autores e coautores dos 41 artigos, a fim de analisarmos como os mesmos se relacionam, já que o diálogo entre distintos autores contribui para difundir cada vez mais as ideias de uma determinada área de estudo. O grafo está esquematizado na Figura 2, onde os vértices em destaque indicam os cinco autores que apresentaram maior centralidade de grau, ou seja, aqueles que conseguem estabelecer mais relações com os demais autores.

A partir do grafo, montou-se uma tabela com os cinco autores que possuem maiores centralidades de grau, bem como a instituição à qual são vinculados (Tabela 3).

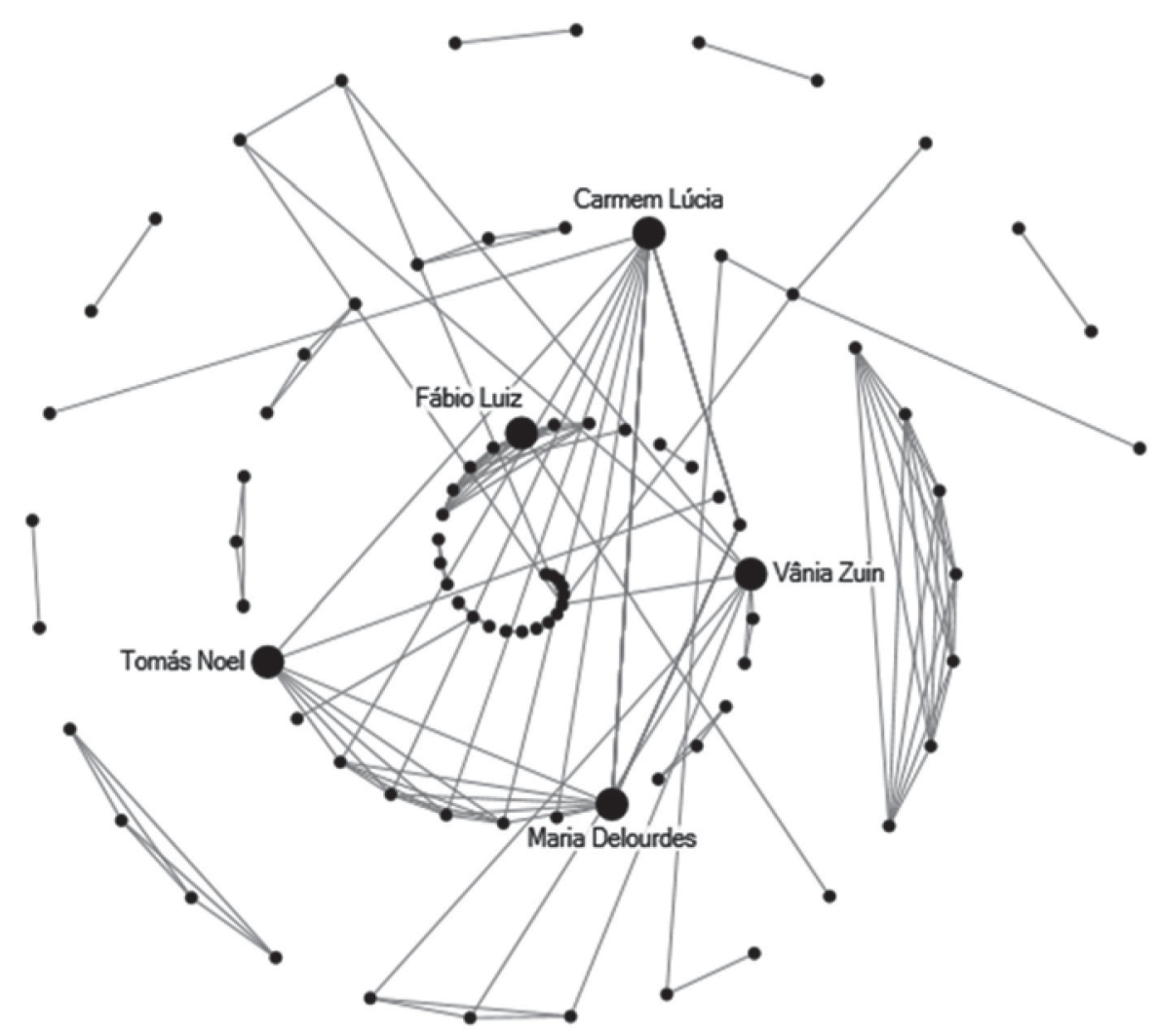

Created with NodeXL (http:I/nodex.codeplex.com)

Figura 2: Grafo gerado a partir dos autores. 
Tabela 3: Medidas de centralidade dos autores

\begin{tabular}{lcc}
\hline Autor & Centralidade de grau & Instituição de vínculo \\
\hline Carmem Lúcia Costa Amaral & 9 & Universidade Cruzeiro do Sul \\
Vânia Gomes Zuin & 8 & Universidade Federal de São Carlos \\
Maria DeLourdes Maciel & 8 & Universidade Cruzeiro do Sul \\
Fábio Luiz de Souza & 7 & Universidade de São Paulo \\
Tomás Noel Herrera Vasconcelos & 7 & Universidade Cruzeiro do Sul \\
\hline
\end{tabular}

O levantamento dos autores de cada artigo e a análise do grafo e da tabela nos permitem avaliar que três dos cinco autores que possuem maior grau de centralidade são vinculados à mesma Universidade e a maioria dos artigos publicados por estes autores são em parceria conjunta ou até com outros professores da mesma Universidade. Isso mostra que o diálogo entre esses autores contribui para os altos graus de centralidade, apesar da endogenia institucional.

Outra constatação relevante é a de que os trabalhos do segundo e do quarto autor da Tabela 3 foram feitos em conjunto com muitos coautores, sendo todos da mesma instituição, favorecendo o alto valor da medida de centralidade de grau.

O estudo das medidas de centralidade de intermediação nos mostra que esses autores também estabelecem boa comunicação com autores de outras sub-redes. No entanto, a investigação dessas medidas dos 86 autores, mostrou que, destes, 72 apresentam centralidade de intermediação igual a zero. Assim, ficou claro que os escritores que publicaram na área de ensino de química com enfoque CTS no Brasil no período de 1996 a 2016 dialogam muito pouco com autores de diferentes instituições de ensino, o que justifica a enorme quantidade de redes desconexas presentes na Figura 2.

Com o intuito de apresentar as contribuições para o ensino CTS das referências de maior relevância utilizadas na elaboração dos artigos sobre ensino de química, selecionamos, dentre 41, as oito obras mais citadas no conjunto pesquisado, como mostra a Tabela 4.

A leitura desses resultados indica o livro Educação em Química: compromisso com a cidadania, de Santos e Schnetzler (2008) como o trabalho mais citado. Analisando o texto dessa obra, identificamos que os autores apresentam como reflexão o objetivo do ensino de química, que é formar cientistas ou cidadãos capazes de interferir na sociedade em que vivem, exercendo sua cidadania. Merece destaque o fato de que os autores dedicam um capítulo ao tema "formação do cidadão e o ensino CTS", em que apresentam "as principais proposições encontradas na literatura internacional sobre a caracterização e implementação do ensino CTS, Ciência, Tecnologia e Sociedade" (Santos e Schnetzler, 2008, p. 59), sendo o provável motivo de ser a obra de maior relevância nesta área.

Utilizando-se do mesmo viés, Santos e Mortimer (2002) apresentam, em seu artigo, uma análise crítica sobre pressupostos de currículos de ensino de ciências com ênfase em CTS, de modo a fornecer subsídios para a elaboração de novos modelos curriculares que alcancem os objetivos educacionais desejados com a abordagem CTS. Nesse contexto, eles fizeram um breve histórico sobre as mudanças curriculares ocorridas entre as décadas de 1970 e 2000, e citam materiais didáticos

Tabela 4: Referências mais citadas sobre o ensino de química nos artigos analisados

\begin{tabular}{lll}
\hline Rank & Número de citações & \multicolumn{1}{c}{ Referência } \\
\hline 1 & 18 & $\begin{array}{l}\text { SANTOS, W. L. P. e SCHNETZLER, R. P. Educação em química: compromisso com a cidadania. ljuí: Unijuí, } \\
2008 .\end{array}$ \\
\hline 2 & 15 & $\begin{array}{l}\text { SANTOS, W. L. P. e MORTIMER, E. F. Uma análise de pressupostos teóricos da abordagem C-T-S (ciência- } \\
\text { tecnologia-sociedade) no contexto da educação brasileira. Ensaio Pesquisa em Educação em Ciências, v. } \\
2, \text { n. 2, p. 110-132, 2002. }\end{array}$ \\
\hline $\mathbf{3}$ & 10 & $\begin{array}{l}\text { AULER, D. e DELIZOICOV, D. Alfabetização científico-tecnológica para quê? Ensaio Pesquisa em Educação } \\
\text { em Ciências, v. 3, n. 2, p. 122-134, 2001. }\end{array}$ \\
\hline $\mathbf{5}$ & 8 & $\begin{array}{l}\text { ACEVEDO DÍAZ, J. A. Cambiando la práctica docente em la enseñanza de las ciencias a través de CTS. } \\
\text { Borrador, Huelva, v. 13, p. 26-30, 1996. }\end{array}$ \\
\hline $\mathbf{6}$ & 7 & $\begin{array}{l}\text { AULER, D. Alfabetização científico-tecnológica: um novo "paradigma"? Ensaio Pesquisa em Educação em } \\
\text { Ciências, v. 5, n. 1, p. 68-83, 2003. }\end{array}$ \\
\hline $\mathbf{8}$ & 6 & $\begin{array}{l}\text { SANTOS, W. L. P. e MORTIMER, E. F. Abordagem de aspectos sociocientíficos em aulas de ciências: } \\
\text { possibilidades e limitações. Investigações em Ensino de Ciências, v. 14, n. 2, p. 191-218, 2009. }\end{array}$ \\
\hline
\end{tabular}


produzidos e recomendações curriculares brasileiras em CTS sugeridas nesse período, além de destacar a evolução tecnológica no mundo contemporâneo e a necessidade de superar os mitos ao redor da ciência, como, por exemplo, o da ciência neutra e salvacionista.

Os mesmos autores publicaram outro artigo em 2009, sendo o sexto trabalho mais citado, que pretende mostrar que a abordagem de aspectos sociocientíficos (ASC) aumenta as interações em sala de aula e facilita a emergência de situações vivenciais dos alunos e a introdução de atitudes e valores em uma perspectiva humanística. O trabalho foi desenvolvido em aulas de química, com professores que utilizavam o livro Química na Sociedade, a fim de saber se esses professores, através de suas práticas docentes, abordavam os ASC para buscarem uma educação científica humanística, com postura dialógica, atingindo um horizonte conceitual e diferentes abordagens comunicativas.

Nessa mesma perspectiva, destacamos o sétimo trabalho mais citado, "Contribuições freireanas para a contextualização no ensino de Química" de Coelho e Marques (2007), que se apoiou nas ideias de Wildson Santos, destacando o ensino de química para a formação da cidadania, e sugere a abordagem científico-tecnológica a partir de temas químicos sociais, buscando uma aproximação com os pressupostos de Paulo Freire. Em seguida, falam sobre o meio ambiente, considerando os aspectos da química verde, e finalizam relacionando estes aspectos com a abordagem CTS, na qual os problemas não devem ser responsabilizados de forma neutra, porque pensar dessa forma significa restringir os mesmos a uma questão técnica, enquanto numa visão CTS de ensino a interferência dos atores sociais é fundamental.

Ainda no viés freiriano, temos como última referência mais citada o livro Pedagogia do Oprimido, escrito por Paulo Freire e que, apesar de ser um livro de 1974, trata de um assunto muito atual e que ainda insiste em existir nas salas de aula: uma educação na qual o professor não ensina o seu aluno a pensar, mas transmite o conhecimento de forma "bancária", em que o estudante é tratado meramente como um depositário, um ser incapaz de produzir conhecimento. $\mathrm{O}$ ideal, porém, segundo o autor, é que o professor problematize sobre a realidade de seu público e o ensine a pensar, caracterizando a educação problematizadora e fazendo com que seu educando se identifique e compreenda-se como um ser social.

Na sequência da análise, temos na terceira posição o trabalho sobre alfabetização científico-tecnológica de Auler e Delizoicov (2001), e ainda, como o quinto mais citado, um artigo que discute o mesmo tema de autoria de Auler (2003). O artigo "Alfabetização científico-tecnológica para quê?" expõe, primeiramente, que o termo "alfabetização científicotecnológica" possui diversos significados, e que os objetivos que os sustentam são diversos, como, por exemplo, a autêntica participação popular em problemáticas que se relacionam com ciência e tecnologia. Os autores trabalham ainda os mitos que norteiam a neutralidade da ciência, bem como analisam as duas perspectivas da alfabetização científico-tecnológica: a reducionista, que evita a problematização da ciência e acaba sendo vista como uma perspectiva ingênua; e a perspectiva ampliada, que se baseia na ideia de que os conceitos são apenas meios para a compreensão do aluno, sendo um referencial freiriano e fazendo com que os mitos sejam superados e os estudantes alcancem a construção do conhecimento e de uma leitura crítica do mundo, buscando compreender as interações CTS.

Enquanto no trabalho em conjunto os autores buscam discutir a importância da alfabetização científico-tecnológica, no outro artigo, Auler (2003) apresenta o mesmo assunto como um paradigma, articulando pressupostos do movimento CTS e de Paulo Freire com os resultados empíricos obtidos em sua tese de doutoramento. Auler (2003) propõe a superação de um ensino propedêutico e disciplinar a partir de um ensino que valorize a abordagem temática.

Finalizamos com o quarto artigo mais citado, Acevedo Díaz (1996), que reflete a respeito da problemática da prática pedagógica dos docentes. $\mathrm{O}$ autor explicita que os projetos curriculares como estão hoje se afastam de uma abordagem CTS que busca alternativas mais centradas no aluno e que parta de um problema relevante para ele a fim de que essa discussão não se esgote ao final da aula. Dessa forma, o autor afirma que é necessário que os docentes mudem suas atuações e se dediquem mais à preparação das aulas, à distribuição do tempo e recursos e atentem para o clima da aula (tanto afetivo quanto metodológico), já que grande parte dos êxitos e dos fracassos dos estudantes se deve ao clima dentro de sala de aula.

Outra visão importante a respeito dos artigos de ensino de química apresentados na Tabela 4 é o fato de que apenas um deles é de origem estrangeira e é considerado como fonte primária na área CTS. Acreditamos que, apesar de existir a dificuldade de se realizar a pesquisa em outro idioma que não seja o materno, Acevedo Díaz é citado devido ao fato do espanhol, sua língua de origem, se aproximar mais do nosso idioma frente a outros.

Além das análises particulares de cada obra, verificamos a relação destas com as referências mais citadas na área CTS no Brasil, que foram elencadas por Chrispino et al. (2013, p. 464), em artigo que inaugura o mapeamento CTS brasileiro usando redes sociais, como pode ser visto na Tabela 5.

Dessa forma, observamos que, dos oito trabalhos mais citados em ensino de química com enfoque CTS, três estão presentes dentre os apontados na Tabela 5: Santos e Mortimer (2002), Auler e Delizoicov (2001) e Acevedo Díaz (1996). Isso mostra que estas obras são extremamente relevantes para pesquisas não só no ensino de química, mas também para outras áreas que buscam se utilizar do enfoque CTS como abordagem de ensino.

Depreende-se que as oito obras mais referenciadas em ensino de química representam o que os pesquisadores da área mais se utilizam para embasar seus trabalhos e, por conta 
Tabela 5: Referências mais citadas na área CTS no Brasil

\begin{tabular}{|c|}
\hline Título \\
\hline $\begin{array}{l}\text { Uma análise de pressupostos teóricos da abordagem C-T-S } \\
\text { (ciência-tecnologia-sociedade) no contexto da educação brasileira. }\end{array}$ \\
\hline $\begin{array}{l}\text { Ciencia, tecnología y sociedad: una introducción al estudio social } \\
\text { de la ciencia y la tecnología. }\end{array}$ \\
\hline $\begin{array}{l}\text { Reflexões para a implementação do movimento CTS no contexto } \\
\text { educacional brasileiro. }\end{array}$ \\
\hline $\begin{array}{l}\text { Interações entre ciência-tecnologia-sociedade no contexto da } \\
\text { formação de professores de ciências. }\end{array}$ \\
\hline $\begin{array}{l}\text { Ciência, tecnologia e sociedade: e o contexto da educação } \\
\text { tecnológica. }\end{array}$ \\
\hline Introdução aos estudos CTS (ciência, tecnologia e sociedade). \\
\hline $\begin{array}{l}\text { Ciência-tecnologia-sociedade: relações estabelecidas por } \\
\text { professores de ciências. }\end{array}$ \\
\hline $\begin{array}{l}\text { Cambiando la práctica docente em la enseñanza de las ciencias } \\
\text { a través de CTS. }\end{array}$ \\
\hline $\begin{array}{l}\text { O ensino de biologia e as relações entre ciência/tecnologia/ } \\
\text { sociedade: o que dizem os professores e o currículo do ensino } \\
\text { médio? }\end{array}$ \\
\hline $\begin{array}{l}\text { O enfoque ciência, tecnologia e sociedade e a aprendizagem } \\
\text { centrada em eventos. }\end{array}$ \\
\hline Teaching science, technology and society. \\
\hline $\begin{array}{l}\text { Educación tecnológica desde una perspectiva CTS: una breve } \\
\text { revisión del tema. }\end{array}$ \\
\hline
\end{tabular}

Alfabetização científico-tecnológica para quê?

\section{Referência}

SANTOS, W. L. P. e MORTIMER, E. F. Ensaio Pesquisa em Educação

em Ciências, v. 2, n. 2, p. 105-115, 2002.

GONZÁLEZ GARCÍA, M. I.; LÓPEZ CEREZO, J. A. e LUJÁN LÓPEZ,

J. L. Madrid: Tecnos, 1996.

AULER, D. e BAZZO, W. A. Ciência \& Educação, v. 7, n. 1, p. 1-13, 2001.

AULER, D. Tese (Doutorado em Educação Científica e Tecnológica).

Universidade Federal de Santa Catarina, Florianópolis, 2002.

BAZZO, W. A. Florianópolis: Ed. da UFSC, 1998.

BAZZO, W. A.; LINSINGEN, I. e PEREIRA, L. T. V. Madrid: OEI, 2003.

AULER, D. e DELIZOICOV, D. Revista Electrónica de Enseñanza de las

Ciencias, v. 5, n. 2, p. 337-355, 2006.

ACEVEDO DÍAZ, J. A. Borrador, Huelva, v. 13, p. 26-30, 1996.

AMORIM, A. C. R. In: Anais do VI Encontro Perspectivas do Ensino de Biologia. São Paulo, SP, 1997.

CRUZ, S. M. S. C. e ZYLBERSZTAJN, A. In: PIETROCOLA, M. (Org.). Ensino de física: conteúdo e epistemologia numa concepção integradora. Florianópolis: Ed. da UFSC, 2001. p. 171-196.

SOLOMON, J. Buckingham: Open University Press, 1993.

ACEVEDO DíAZ, J. A. Alambique: Didáctica de las Ciencias Experimentales, v. 2, n. 3, p. 75-84, 1995.

AULER, D. e DELIZOICOV, D. Ensaio Pesquisa em Educação em Ciências, v. 3, n. 1, p. 105-115, 2001. disso, parecem ser de leitura fundamental para aqueles que desejam iniciar-se nos estudos da abordagem CTS. No entanto, a análise desses trabalhos nos permitiu concluir que cinco dos oito apresentam, em perspectivas distintas, as mesmas ideias: três trabalhos são de autoria de Wildson Santos (2002, 2008, 2009) e um deles vai ao encontro das ideias de Freire (1974), que também é uma das referências apontadas e serve de embasamento para o sétimo trabalho mais citado. Dessa forma, podemos inferir que, apesar de serem obras tidas como consensuais, é fundamental que os pesquisadores da área ampliem suas fontes de consulta a fim de não ficarem limitados a uma mesma linha de pensamento.

Além da tabela das obras mais citadas, foram elencados também os autores mais referenciados, a fim de analisarmos qual a influência dos mesmos no ensino de química e suas relações com CTS. Compreende-se, assim, que cada autor apresenta particularidades que podem contribuir para melhor fundamentação teórica acerca do tema, sendo de extrema importância para os estudiosos desta área.

A Tabela 6 evidencia o resultado dos autores mais citados e quantas vezes eles apareceram nos 41 artigos analisados.

A partir da Tabela 6, vemos que Wildson Santos, além de possuir a obra mais referenciada, é o autor mais citado.
Tabela 6: Autores mais citados nos artigos analisados

\begin{tabular}{lcl}
\hline Rank & $\begin{array}{c}\text { Número de } \\
\text { citações }\end{array}$ & \multicolumn{1}{c}{ Autor } \\
\hline $\mathbf{1}$ & 73 & $\begin{array}{l}\text { Wildson Luiz Pereira dos Santos (Santos, } \\
\text { W. L. P.) }\end{array}$ \\
\hline $\mathbf{2}$ & 33 & \begin{tabular}{l} 
Decio Auler (Auler, D.) \\
\hline $\mathbf{3}$
\end{tabular} \\
\hline $\mathbf{4}$ & 24 & $\begin{array}{l}\text { Jose Antonio Acevedo Díaz (Acevedo } \\
\text { Díaz, J. A.) }\end{array}$ \\
\hline $\mathbf{5}$ & 19 & $\begin{array}{l}\text { Eduardo Fleury Mortimer (Mortimer, } \\
\text { E. F.) }\end{array}$ \\
\hline $\mathbf{6}$ & 18 & Paulo Freire (Freire, P.) \\
\hline $\mathbf{7}$ & 14 & Demetrio Delizoicov (Delizoicov, D.) \\
\hline $\mathbf{8}$ & 12 & Glen S. Aikenhead (Aikenhead, G. S.) \\
\hline
\end{tabular}

Wildson Santos (1961-2016) doutorou-se em Educação, tendo como último vínculo a Associação Ibero-Americana CiênciaTecnologia-Sociedade (AIA-CTS). Possui diversos trabalhos publicados na área, evidenciando uma participação ativa.

Décio Auler é doutor em Educação e, apesar de sua experiência profissional ter ênfase em currículo, é atuante nos temas de CTS, Paulo Freire e educação em ciências. Possui diversas 
obras nas áreas citadas e, atualmente, desenvolve um trabalho de pesquisa sobre as dimensões da não neutralidade da ciência, tema que é muito discutido quando se trabalha a tríade ciência, tecnologia e sociedade.

Alguns trabalhos de Auler foram escritos em parceria com Demetrio Delizoicov, que aparece como o sexto autor mais citado. Delizoicov é doutor em Educação e participa de um projeto de pesquisa sobre Paulo Freire. Ele não possui muitos trabalhos sobre ensino CTS, embora sua participação na área seja ativa, uma vez que sua última publicação acerca do tema foi em 2015. É importante ressaltar, contudo, que grande parte de sua produção bibliográfica tem estreita relação com a abordagem CTS.

Acevedo Díaz é licenciado em Ciências com enfoque em Química e é membro da Organização de Estados Iberoamericanos (OEI) no programa de CTS, sendo o autor de artigo estrangeiro mais bem posicionado na pesquisa de ensino CTS brasileiro (Chrispino et al., 2013). Seus principais temas de investigação atuais se concentram na educação CTS no ensino de ciências e nas atitudes relacionadas com a ciência e a alfabetização científica e tecnológica para a participação cidadã de todas as pessoas.

O quarto autor mais citado foi Eduardo Mortimer, que é doutor em Educação e, apesar de não dialogar diretamente com o ensino CTS, produz muito sobre ensino de ciências. Além disso, é coautor em diversos trabalhos de Wildson Santos.

Na sequência, temos o educador Paulo Freire que, embora formado em Direito, teve participação marcante na área da Educação, na qual desenvolveu um método inovador de alfabetização. Não faz nenhuma referência direta à área de ensino CTS, mas, por sua atuação na formação de cidadãos transformadores da ordem social, econômica e política, seus pressupostos são aproximados aos de CTS e assim são usados para fundamentar as ideias de autores de relevância que escrevem sobre o ensino de química na área CTS.

O sétimo colocado foi Aikenhead, que é doutor em Educação Científica e tem grande atuação no campo de ensino CTS, sendo considerado como fonte primária para os pesquisadores da área. Possui muitos trabalhos publicados sobre o assunto, como artigos e capítulos de livro em que apresenta suas concepções sobre ciência, tecnologia e sociedade.

Por fim, destacamos Attico Chassot como o oitavo autor mais referenciado nos 41 artigos analisados. É doutor em Educação e não possui trabalhos publicados sobre ensino CTS, mas é pesquisador de alfabetização científica e história e filosofia da ciência, temas importantes para a compreensão da abordagem CTS.

É oportuno ressaltar que, a partir da análise das Tabelas $4 \mathrm{e}$ 6 , podemos observar que seis dos autores mais citados também são autores das referências mais relevantes (Wildson Santos, Décio Auler, Jose Antonio Acevedo Díaz, Eduardo Fleury Mortimer, Paulo Freire e Demetrio Delizoicov). Com isso, entendemos que estes pesquisadores possuem grande influência para o ensino de química com enfoque CTS no Brasil.

\section{Considerações Finais}

O ensino de ciências com enfoque CTS está diretamente relacionado com a possibilidade de promover a formação de indivíduos capazes de fazer escolhas de forma democrática. De acordo com Santos e Schnetzler (2008, p. 68), um dos objetivos do ensino CTS "relaciona-se à solução de problemas da vida real que envolvem aspectos sociais, tecnológicos, econômicos e políticos" enquanto outro "refere-se à compreensão da natureza da ciência e do seu papel na sociedade".

No entanto, a abrangência dessa área pode levar a uma insegurança do professor sobre quais estratégias seguir. Com isso, a fim de obter um aporte teórico substancial, é necessário que o educador tenha acesso às obras mais relevantes nessa área. Para o ensino de biologia, ficou claro na pesquisa de Rocha et al. (2017) que os autores dessa área se relacionam entre si, sendo as obras mais relevantes para leitura diferentes das obras mais importantes para o ensino CTS de uma maneira geral. Em relação ao ensino de química no ensino CTS brasileiro, temos oito obras de grande destaque que fornecem embasamentos para a implementação desta abordagem. Em contrapartida, é importante destacar que a maioria destas referências compartilha da mesma família de ideias, o que pode limitar a pesquisa e, consequentemente, a prática do docente, sendo importante que o mesmo não se atenha apenas a essas fontes.

Além disto, chamamos a atenção para o fato de que, dessas oito referências, apenas uma é considerada fonte primária (Acevedo Díaz, 1996), ou seja, os autores dos 41 artigos analisados se embasam, em sua maioria, em fontes secundárias e não nas primárias, seja por facilidade de acesso aos trabalhos ou pela dificuldade do idioma original dessas fontes, uma vez que a maioria é de língua estrangeira. Este fato também se comprova quando verificamos que, dentre os oito autores mais citados, apenas dois são fontes primárias de pesquisa.

Outro ponto que merece destaque é a importância da escolha das palavras-chave de um trabalho, uma vez que estas são instrumentos facilitadores do acesso ao mesmo. Percebemos, em nossa pesquisa, a presença de palavras-chave sem vínculos com o conjunto, pertencendo a temas muito específicos ou muito singulares, e que se vinculam por apenas uma ou duas palavras-chave. Acrescemos que encontramos as mesmas dificuldades que outros autores de trabalhos que se utilizam de palavras-chave, em função da falta de descritores para a área de CTS, fazendo com que exista um grande número de palavras-chave muitas vezes sinônimas ou similares.

A partir da análise dos resultados apresentados neste trabalho, inferimos que o ensino de química ainda possui pouca representatividade no ensino CTS brasileiro, visto que, dos 244 artigos contidos na base de dados CTS, apenas 41 são da área. Este fato pode ocorrer pela dificuldade da mudança da prática docente para o uso da abordagem CTS.Contextualizar, promover o ensino interdisciplinar e a alfabetização científica, bem como relacionar os aspectos sociocientíficos, são fatores 
que possibilitam ao professor desconstruir conceitos e, assim, ressignificá-los. No entanto, apesar dessa transformação ser complexa, acreditamos que ela seja necessária, já que a vivência de novas experiências faz com que o professor adquira " $a u$ tonomia e segurança para a adoção de novas metodologias" (Santos e Mortimer, 2009, p. 214) dentro do ensino CTS.

\section{Nota}

${ }^{1}$ A versão utilizada está disponível no site http://nodexl. codeplex.com

\section{Referências}

ACEVEDO DÍAZ, J. A. Cambiando la práctica docente em la enseñanza de las ciencias a través de CTS. Borrador, Huelva, v. 13, p. 26-30, 1996.

AIKENHEAD, G. Educación ciencia-tecnología-sociedad (CTS): una buena idea como quiera que se le llame. Educación Química, v. 16, n. 2, p. 114-124, 2005.

AULER, D. Alfabetização científico-tecnológica: um novo "paradigma"? Ensaio Pesquisa em Educação em Ciências, v. 5, n. 1, p. 68-83, 2003.

Enfoque ciência-tecnologia-sociedade: pressupostos para o contexto brasileiro. Ciência \& Ensino, v. 1, s. p., 2007.

e DELIZOICOV, D. Alfabetização científico-tecnológica para quê? Ensaio - Pesquisa em Educação em Ciências, v. 3, n. 2, p. 122-134, 2001.

BARNES, J. A. Class and committees in a norwegian island parish. Human Relations, v. 7, n.1, p. 39-58, 1954.

BAZZO, W. A.; LISINGEN, I. e PEREIRA, L. T. V. Introdução aos estudos CTS (ciencia, tecnología e sociedade). Madrid: OEI, 2003.

CHRISPINO, A.; LIMA, L. S.; ALBUQUERQUE, M. B.; FREITAS, A. C. C. e SILVA, M. A. F. B. A área CTS no Brasil vista como rede social: onde aprendemos? Ciência \& Educação, v. 19, n. 2, p. 455479, 2013.

COELHO, J. C. e MARQUES, C. A. Contribuições freireanas para contextualização no ensino de química. Ensaio Pesquisa em Educação em Ciências, v. 9, n. 1, p. 59-75, 2007.
CUTCLIFFE, S. H. Ideas, máquinas y valores: los estudios de ciencia, tecnología y sociedad. Barcelona: Anthropos Editorial, 2003.

FREIRE, P. Pedagogia do oprimido. São Paulo: Paz e Terra, 1974.

MANASSERO, M. A. e VÁZQUEZ, Á. Instrumentos y métodos para la evaluación de las actitudes relacionadas com la ciencia, la tecnología y la sociedad. Enseñanza de las Ciencias: Revista de Investigación y Experiências Didácticas, v. 20, n. 1, p. 15-27, 2001.

MELO, T. B.; PONTES, F. C. D. C.; ALBUQUERQUE, M. B.; SILVA, M. A. F. B. e CHRISPINO, A. Os temas de pesquisa que orbitam o enfoque CTS: uma análise de rede sobre a produção acadêmica brasileira em Ensino. Revista Brasileira de Pesquisa em Educação em Ciências, v. 16, n. 3, p. 587-606, 2016.

ROCHA, M. L.; GONZALEZ, A. H. G.; BRUNO, N. V. e CHRISPINO, A. Representatividade da biologia em CTS por meio de análise por redes sociais. Revista Contexto \& Educação, v. 32, n. 102, p. 81-99, 2017.

SANTOS, W. L. P. e AULER, D. CTS e educação científica: desafios, tendências e resultados de pesquisa. Brasília: Editora Universidade de Brasília, 2011.

e MORTIMER, E. F. Abordagem de aspectos sociocientíficos em aulas de ciências: possibilidades e limitações. Investigações em Ensino de Ciências, v. 14, n. 2, p. 191-218, 2009.

e ___ Uma análise de pressupostos teóricos da abordagem C-T-S (ciência-tecnologia-sociedade) no contexto da educação brasileira. Ensaio - Pesquisa em Educação em Ciências, v. 2, n. 2, p. 110-132, 2002.

e SCHNETZLER, R. P. Educação em química: compromisso com a cidadania. Ijuí: Unijuí, 2008.

SILVA, J. B. D. e PLOHARSKI, N. R. B. A metodologia de ensino utilizada pelos professores da EJA - $1^{\circ}$ segmento em algumas escolas da rede municipal de ensino de Curitiba. In: Anais do X Congresso Nacional De Educação. Curitiba, PR, 2011.

STRIEDER, R. B.; SILVA, K. M. A.; FERNANDES SOBRINHO, M. e SANTOS, W. L. P. A educação CTS possui respaldo em documentos oficiais brasileiros? ACTIO: Docência em Ciências, v. 1, n. 1, p. 87-107, 2016. 